\title{
Reisen zu Coronazeiten
}

Wer heut' verreiste zu Coronazeiten, Erlebte da gar arge Pleiten.

Quarantäne, Schnelltest und so weiter

Waren beim Reisen dein ständiger Begleiter.

Das kann's nicht sein, hab' ich mir dann gesagt

Und Fernreisen aufs nächste Jahr vertagt.

Die Lösung, scheint's, hab' ich gefunden:

Ich werde dieses Jahr mein Innerstes erkunden.

Ein Atemzug, schon bin ich drin,

Der Zunge lang bis zum Check-in.

Vor den Tonsillen wird man kontrolliert,

Doch sieh einer an, die sind schon operiert.

Nun geht es weiter runter den Ösophagus

Leider zu Fuss und nicht bequem im Omnibus.

Beim Mageneingang gibt's Poulet süss-sauer,

Die Peristaltik ist hier schon etwas rauer.

Und im Zwölffingerdarm macht man ne kurze Pause,

Hier gibt's zur Stärkung eine kühle Brause.

Kurz steckt man schnell noch seine Nase

In die prallvolle Gallenblase.

Und gleich daneben beim schlanken Pankreas

Gibt's zum Dessert ne frische Ananas.

Und weiter dann, beim Dickdarm angeklopft,

Hofft man, dass er nicht wieder ist verstopft.

Doch heut scheint er ganz munter

Und trägt uns weiter runter.

Noch schnell ein Blick auf die Appendix,

Die liegt nur da und taugt zu nix.

Bis man zwischen zwei Hämorrhoiden hängt

Und in einer Mariske sich verfängt.

Schlussendlich ist dies auch egal,

Denn die Reise endet hier anal.

Dr. med. Michael Knobloch, Zürich 